\title{
Functional hit 1 (FH1)-based rapid and efficient generation of functional hepatocytes from human mesenchymal stem cells: a novel strategy for hepatic differentiation
}

\author{
Sang Luo^, Yang Ai, Shuai Xiao, Ben Wang, Yefu Wang \\ State Key Laboratory of Virology, School of Life Sciences, Wuhan University, Wuhan, China \\ Contributions: (I) Conception and design: S Luo; (II) Administrative support: Y Wang; (III) Provision of study materials or patients: S Xiao; (IV) \\ Collection and assembly of data: S Luo; (V) Data analysis and interpretation: Y Ai, S Xiao, B Wang; (VI) Manuscript writing: All authors; (VII) Final \\ approval of manuscript: All authors. \\ Correspondence to: Yefu Wang. State Key Laboratory of Virology, School of Life Sciences, Wuhan University, Wuhan, China. Email: wangyefu@whu.edu.cn.
}

Background: Because the liver is central to the physiology of the body, primary hepatocytes are widely used in liver pathology and physiological research, such as liver drug screening, bioartificial liver support system, and cell therapy for liver diseases. However, the source of primary hepatocytes is limited. We describe a novel non-transgenic protocol that facilitates the rapid generation of hepatocyte-like cells from human umbilical cord-derived mesenchymal stem cells (hUC-MSCs), providing a new source of functional hepatocytes.

Methods: In this study, we used hUC-MSCs and human induced pluripotent cells (iPSCs) derived mesenchymal stem cells (iMSCs) to investigate the new induction strategy. Passage 3 MSCs were induced into hepatocyte-like cells using small-molecule compounds combined with cell factors in vitro. Functional hit 1 (FH1), a promising small molecule compound was achieved to replace HGF in the hepatocyte maturation stage to induce the hepatocyte-like cells differentiation.

Results: We rapidly induced hUC-MSCs and human iMSCs into hepatocyte-like cells within 10 days in vitro, and the cells were morphologically similarly to both hepatocytes derived from the hepatocyte growth factor (HGF)-based method and the primary hepatocytes. They expressed mature hepatocyte special genes and achieved functions such as glycogen storage, albumin expression, urea secretion, cytochrome $\mathrm{P} 450$ activity, Low-density lipoprotein (LDL) uptake, and indocyanine green (ICG) uptake.

Conclusions: We successfully established a small-molecule protocol without using HGF to differentiate MSCs into hepatocyte-like cells, which provides a rapid and cost-effective platform for in vitro studies of liver disease.

Keywords: Hepatocyte differentiation; human mesenchymal stem cells (human MSCs); Functional hit 1 (FH1)

Submitted May 19, 2021. Accepted for publication Jun 25, 2021.

doi: 10.21037/atm-21-2829

View this article at: https://dx.doi.org/10.21037/atm-21-2829

\section{Introduction}

The liver, as the most critical metabolic center of the human body, is involved in various physiological processes. Liver failure is one of the common diseases that seriously endanger human life. The main causes are drugs, viruses, and toxins, and the clinical manifestations are liver dysfunction, coagulation dysfunction, hepatic encephalopathy, multiple organ failure, and other

$\wedge$ ORCID: 0000-0003-2291-4295. 
symptoms (1). The disease develops rapidly, and the mortality rate is alarmingly high. Orthotopic liver transplantation (OLT) is the most effective treatment, but because the number of organ donors is far fewer than the number of liver transplantation patients, many patients die while on the waiting list(2). The development of stem cell technology is a promising strategy for obtaining seed cells for liver diseases $(3,4)$.

Mesenchymal stem cells (MSCs) are a type of adult pluripotent stem cell that originate from the mesoderm and are capable of self-renewal and differentiation along multiple lineages (including hepatocytes) (5). They mainly exist in connective tissue and interstitial tissue, especially in the umbilical cord (6-8). Human umbilical cord-derived MSCs (hUC-MSCs) have certain attractive qualities such as plastic attachments, positive expression of unrestricted MSC markers, and tri-mesodermal differentiation to osteoblasts, chondrocytes, and adipocytes (9). Compared with embryonic stem cells (ESCs), the use of hUC-MSCs has no ethical restrictions and there is low immunogenicity (10). Thus, this strategy can be widely used in clinical cell therapy and scientific research.

To date, there are four main methods for inducing hUCMSCs to differentiate into hepatocytes: adding compounds and cytokines (11), genetic modification (12), defining the culture microenvironment, and improving the physical parameters of culture $(13,14)$. However, because these methods are costly, time-consuming, and inefficient, they cannot meet the clinical need for primary hepatocytes (15).

Small molecular chemical compounds have been reported effectively to interfere with signals involved in early development and showed potential to promote the efficiency of human induced pluripotent stem cells (hiPSCs) and human embryonic stem cells (hESCs)differentiation (16-18). Wnt signaling activation is indispensable for the definitive endoderm (DE)formation, which is the first step of hepatocyte differentiation from stem cells $(19,20)$. GS3K inhibitor such as CHIR99021 is beneficial for Wnt signaling activation (21). Activin/nodal signaling can induce the original intestinal development in hepatocyte precursor induction step, which is regulated by IDE 1 (22).

Functional hit 1 (FH1) is a small molecule (SM), belonged to the liver hit class of induced functional proliferation of primary human hepatocytes in vitro, which can enhance the functions of cultured hepatocytes and promote hepatocyte differentiation (23). It has been used successfully to induce the differentiation of hiPSCs and hESCs to hepatocytes in vitro (24). Therefore, we hypothesized that FH1 could replace hepatocyte growth factor (HGF) to promote human MSCs differentiation.

In this study, we firstly confirmed that hUC-MSCs can be differentiation into hepatocyte -like cells according to the adipose-derived MSCs (AD-MSCs) hepatogenic differentiation protocol (25). Then, we used FH1 replace HGF that added in the hepatocyte maturation stage to generation the hepatocyte-like cells from hepatic progenitor cells. We successfully designed a modified strategy to direct hepatocyte differentiation from MSCs [including hUCMSCs and human induced pluripotent cells (iPSCs)-derived mesenchymal stem cells MSCs (iMSCs)], with the aim of producing functional hepatocyte-like cells that can express hepatic-specific markers and show primary hepatocyte biological functions, as a cost-effective strategy to generate human MSCs-derived hepatocytes for cell therapy and liver diseases. We present the following article in accordance with the MDAR reporting checklist (available at https:// dx.doi.org/10.21037/atm-21-2829).

\section{Methods}

\section{Culture of bUC-MSC and human iMSC}

hUC-MSC (Nuwacell Biotechnologies Co., Ltd., RC02003) and human induced pluripotent stem cellderived MSC (hiPSC-MSC Nuwacell Biotechnologies Co., Ltd., RC 1005) were cultured in serum free human MSC (SF hMSC) culture medium (Nuwacell ${ }^{\mathrm{TM}}$ ncMission Basal Medium, Nuwacell Biotechnologies Co., Ltd., RP020101) and supplement (Nuwacell ${ }^{\mathrm{TM}}$ ncMission Supplement, Nuwacell Biotechnologies Co., Ltd., RP02010-2) at $37{ }^{\circ} \mathrm{C}$ in a humidified atmosphere with $5 \% \mathrm{CO}_{2}$.

\section{Analysis of cytotoxicity}

A total of 5,000 hepatic progenitor cells were replated and cultured in 96-well culture plates for $24 \mathrm{~h}$. The cytotoxicity of FH1 was assessed through its addition to the culture medium at $3,7.5,15,30$, and $60 \mu \mathrm{M}$. All cultures were maintained at $37^{\circ} \mathrm{C}$ for $72 \mathrm{~h}$ in a humidified atmosphere with $5 \% \mathrm{CO}_{2}$. The effects of $\mathrm{FH} 1$ on cell viability were quantified using a cell-counting kit (Abmole).

\section{Hepatocyte differentiation in vitro}

hUC-MSC and human iMSC at passage three were seeded in six wells at a density of $1.5-3 \times 10^{4} / \mathrm{cm}^{2}$ at $37{ }^{\circ} \mathrm{C}$ with 
$5 \% \mathrm{CO}_{2}$. These plates were coated with $0.1 \%$ gelatin, and the cells were cultured in an expansion medium. For a small molecule with HGF-induced hepatocytelike cell protocol, we used the adipose-derived stem cells hepatogenic differentiation method (25). Briefly, when the cells reached $100 \%$ confluence, they were incubated with Iscove's Modified Dulbecco's Medium (IMDM, Gibco) containing $1 \mu \mathrm{M}$ ATRA for $24 \mathrm{~h}$. In the following $24 \mathrm{~h}$, cells were incubated with IMDM containing $100 \mathrm{nM}$ IDE1, $3 \mu$ M CHIR99021, and $10 \mu$ M LY294002 (Abmole). Subsequently, the cells were incubated with serum-free IMDM containing $100 \mathrm{nM}$ IDE1, $10 \mu \mathrm{M}$ LY294002, $250 \mathrm{nM}$ LDN-193189 (Abmole), and $20 \mathrm{ng} / \mathrm{mL}$ basic fibroblast growth factor (bFGF) (PeproTech) for 2 days, and then changed to serum-free IMDM containing $100 \mathrm{nM}$ IDE1, $10 \mu \mathrm{M}$ LY294002, and $20 \mathrm{ng} / \mathrm{mL}$ bFGF for $24 \mathrm{~h}$. The medium was changed to HBM (Lonza) supplemented with $150 \mathrm{ng} / \mathrm{mL}$ HGF (PeproTech), $20 \mathrm{ng} / \mathrm{mL} \mathrm{bFGF,}$ $30 \mathrm{ng} / \mathrm{mL}$ OSM (PeproTech), $2 \times 10^{-5} \mathrm{~mol} / \mathrm{L}$ dexamethasone (Dex, Abmole), and 1\% ITS-X (Sigma-Aldrich). The differentiation medium was changed every 2 days. For a small molecule with FH1, we added it at the hepatocyte-like cell differentiation stage with the concentration at $15 \mu \mathrm{M}$. For the growth factor-induced hepatocyte-like cell protocol, we used a previously described protocol (26). Briefly, cells were cultured in serum-free IMDM supplemented with $10 \mathrm{ng} / \mathrm{mL} \mathrm{bFGF}, 20 \mathrm{ng} / \mathrm{mL}$ epidermal growth factor (EGF), $100 \mu \mathrm{g} / \mathrm{mL}$ streptomycin, and $100 \mathrm{U} / \mathrm{mL}$ penicillin for 3 days. Then, the cells were incubated with serumfree IMDM $10 \mathrm{ng} / \mathrm{mL}$ bFGF, $40 \mathrm{ng} / \mathrm{mL}$ HGF, and $5 \mathrm{mM}$ nicotinamide for 7 days. Finally, the medium changed to serum-free IMDM containing $10 \mathrm{ng} / \mathrm{mL}$ OSM, $1 \times 10^{-8}$ dexamethasone and $1 \%$ ITS-X for 14 days.

\section{$R N A$ isolation and gene expression analysis}

At the end of each differentiation stage, total RNA was isolated from the cells using the MiniBEST Universal RNA Extraction kit (Takara) in accordance with the manufacturer's instructions. cDNA was synthetized with PrimeScript ${ }^{\mathrm{TM}}$ RT reagent kit, gDNA Eraser (Perfect Real Time) ( Takara), and reverse transcribed using a PrimeScript reverse transcriptase (Takara). The cDNA was then amplified by fluorescent quantitative real-time PCR (q RT-PCR). Q RT-PCR analysis was performed on an ABI Prism 7500 Sequence Detection System (Applied Biosystems) using the TB Green ${ }^{\circledR}$ Premix Ex Taq ${ }^{\mathrm{TM}}$ II (Takara). GAPDH expression was used as the internal standard. Primer sequences are provided in Table 1. All data were calculated as the mean of at least three independent experiments.

\section{Immunofluorescence}

The cells were fixed with $4 \%$ paraformaldehyde for $15 \mathrm{~min}$, and soaked in phosphate-buffered saline (PBS) for $3 \mathrm{~min}$; $0.5 \%$ Triton X-100 (prepared with PBS) was transparent for $20 \mathrm{~min}$ at room temperature; the cells were then soaked in PBS three times and normal goat serum was dripped onto the cells, which were sealed at room temperature for $30 \mathrm{~min}$; the sealing solution was adsorbed with absorbent paper, the cells were incubated at $4{ }^{\circ} \mathrm{C}$ overnight with the following primary antibody: rabbit anti-human FoxA2 (1:200), mouse anti-human Sox17 (1:200), rabbit antihuman AFP (1:100), mouse anti-human HNF4 $\alpha$ (1:500), rabbit anti-human ALB (1:200), mouse anti-human A1AT (1:100). After three washes for 3 min with PBS on the second day, the diluted fluorescent secondary antibody Goat anti-rabbit IgG (1:100) or Goat anti-mouse IgG (1:100) was added at the appropriate concentration, the cells were incubated at $37^{\circ} \mathrm{C}$ for $1 \mathrm{~h}$, and then washed three times with PBS. DAPI was used to stain the cell nuclei. Image acquisition and processing were performed using a fluorescence microscope (Olympus). The positive cells were counted using IPP6.0 software. Detailed information of all antibodies is given in Table 2 .

\section{Western blot}

Cells were dissolved in a RIPA lysis buffer, supplemented with protease inhibitor cocktail (Abmole), and after centrifugation at $12,000 \mathrm{~g}$ for $10 \mathrm{~min}$ at $4{ }^{\circ} \mathrm{C}$, the supernatant was collected. The proteins were then resolved by $10 \%$ SDS-PAGE gel and electro-transferred to nitrocellulose membranes (EMS Millipore). The membrane was blocked with $5 \%$ skim fat milk in PBS with $0.1 \%$ Tween 20 for $1 \mathrm{~h}$ at room temperature, and incubated with the relevant primary antibodies overnight at $4{ }^{\circ} \mathrm{C}$. Following washing in TBS-T, the membranes were incubated with the appropriate secondary antibody for $1 \mathrm{~h}$ at room temperature. Human GAPDH was used as the control of protein loading. Antibody used for western blot were as follows: rabbit antihuman AFP (1:1,000), rabbit anti-human ALB (1:5,000), mouse anti-human A1AT (1:100), rabbit anti-human HNF4 $\alpha(1: 1,000)$, mouse anti-human NTCP $(1: 1,000)$, mouse anti-human FXR $(1: 1,000)$, goat anti-rabbit IgG- 
Table 1 Primers used for real-time quantitative PCR

\begin{tabular}{|c|c|}
\hline Gene & Sequence (5' to $\left.3^{\prime}\right)$ \\
\hline \multirow[t]{2}{*}{ GAPDH } & Forward: ACCATCTTCCAGGAGCGAGAT \\
\hline & Reverse: ATGACGAACATGGGGGCATC \\
\hline \multirow[t]{2}{*}{ SOX2 } & Forward: CCATGCAGGTTGACACCGTTG \\
\hline & Reverse: TCGGCAGACTGATTCAAATAATACAG \\
\hline \multirow[t]{2}{*}{ SOX17 } & Forward: GGCGCAGCAGAATCCAGA \\
\hline & Reverse: CCACGACTTGCCCAGCAT \\
\hline \multirow[t]{2}{*}{ FOXA2 } & Forward: TGCACTCGGCTTCCAGTATG \\
\hline & Reverse: CGTGTTCATGCCGTTCATCC \\
\hline \multirow[t]{2}{*}{ LGR5 } & Forward: GAGGAGTTACGTCTTGCGGG \\
\hline & Reverse: AAACAGCTTGGGGGCACATA \\
\hline \multirow[t]{2}{*}{ GATA4 } & Forward: TCCAAACCAGAAAACGGAAGC \\
\hline & Reverse: GCCCGTAGTGAGATGACAGG \\
\hline \multirow[t]{2}{*}{$A F P$} & Forward: AAATGCGTTTCTCGTTGCTT \\
\hline & Reverse: GCCACAGGCCAATAGTTTGT \\
\hline \multirow[t]{2}{*}{$A L B$} & Forward: GCACAGAATCCTTGGTGAACAG \\
\hline & Reverse: ATGGAAGGTGAATGTTTCAGCA \\
\hline \multirow[t]{2}{*}{$H N F 4 \alpha$} & Forward: ACTACATCAACGACCGCCAGT \\
\hline & Reverse: ATCTGCTCGATCATCTGCCAG \\
\hline \multirow[t]{2}{*}{ CK18 } & Forward: CACAGTCTGCTGAGGTTGGA \\
\hline & Reverse: GAGCTGCTCCATCTGTAGGG \\
\hline \multirow[t]{2}{*}{ CK19 } & Forward: TGAGGAGGAAATCAGTACGCT \\
\hline & Reverse: CGACCTCCCGGTTCAATTCT \\
\hline \multirow[t]{2}{*}{$A 1 A T$} & Forward: AGGTGCCTATGATGAAGCGT \\
\hline & Reverse: TGGCAGACCTTCTGTCTTCATT \\
\hline \multirow[t]{2}{*}{$A L B$} & Forward: GCACAGAATCCTTGGTGAACAG \\
\hline & Reverse: ATGGAAGGTGAATGTTTCAGCA \\
\hline \multirow[t]{2}{*}{ APOA2 } & Forward: GTTCGGAGACAGGCAAAGGA \\
\hline & Reverse: TCAAAGTAAGACTTGGCCTCGG \\
\hline \multirow[t]{2}{*}{ ASGR1 } & Forward: CACCATCAGCTCAGAAAAGGGC \\
\hline & Reverse: ТTСТTСССАСАТТGССТСССТG \\
\hline \multirow[t]{2}{*}{ CYP1A2 } & Forward: ATGTGAGCAAGGAGGCTAAGG \\
\hline & Reverse: GGCAGTCTCCACGAACTCA \\
\hline \multirow[t]{2}{*}{ CYP1A1 } & Forward: CAAGGGGCGTTGTGTCTTTG \\
\hline & Reverse: GTCGATAGCACCATCAGGGG \\
\hline
\end{tabular}

Table 1 (continued)
Table 1 (continued)

\begin{tabular}{ll}
\hline Gene & Sequence (5' to $\left.3^{\prime}\right)$ \\
\hline CYP2B6 & Forward: TCTCCTTAGGGAAGCGGATTTG \\
& Reverse: GCAGGAAGCGGATCTGGTAT \\
CYP2D6 & Forward: TGAAGGATGAGGCCGTCTGGGAGA \\
& Reverse: CAGTGGGCACCGAGAAGCTGAAGT \\
CYP2C9 & Forward: CAAGATTTGAGCAGCCCCTG \\
& Reverse: TGGTTGTGCTTTTCCTTCTCCA \\
CYP3A4 & Forward: GTGGGGCCTTTGTCAGAACT \\
& Reverse: TGGGCAAAGTCACAGTGGAT \\
NTCP & Forward: CCTCAAATCCAAACGGCCAC \\
& Reverse: TGGCAGAGAGAACTGTGACG \\
FXR & Forward: ATGCAAAGAGATGGGAATGTGG \\
& Reverse: TCGCAAGTCACGACCTTCAC \\
\hline
\end{tabular}

HRP secondary antibody $(1: 10,000)$, goat anti-mouse IgGHRP secondary antibody $(1: 10,000)$, monoclonal antibodies against human GAPDH were used as a control of protein loading. Detailed information of all antibodies is given in Table 2.

\section{Periodic acid-Schiff (PAS) staining}

Cells at the endpoint of the differentiation stage were stained using a PAS kit (Beijing Solarbio Science \& Technology Co., Ltd.) for glycogen analysis. According to the instructions, cells were fixed and oxidized for $15 \mathrm{~min}$. The sample was washed twice with water and then washed three times with deionized water. PAS reagent was added and then incubated in the dark at room temperature. After washing with flowing water for $2 \mathrm{~min}$, Mayer's hematoxylin staining solution was added and the cells were visualized by light microscopy.

\section{Cellular uptake of indocyanine green}

ICG is a cyanine dye that is taken up exclusively by mature hepatocytes and is used widely to test hepatic function in clinical diagnosis. ICG (Abmole) was dissolved in DMSO to prepare a stock solution of $10 \mathrm{mg} / \mathrm{mL}$ and then freshly diluted in culture medium to a final concentration of 
Table 2 Antibodies used for immunofluorescence and western blotting

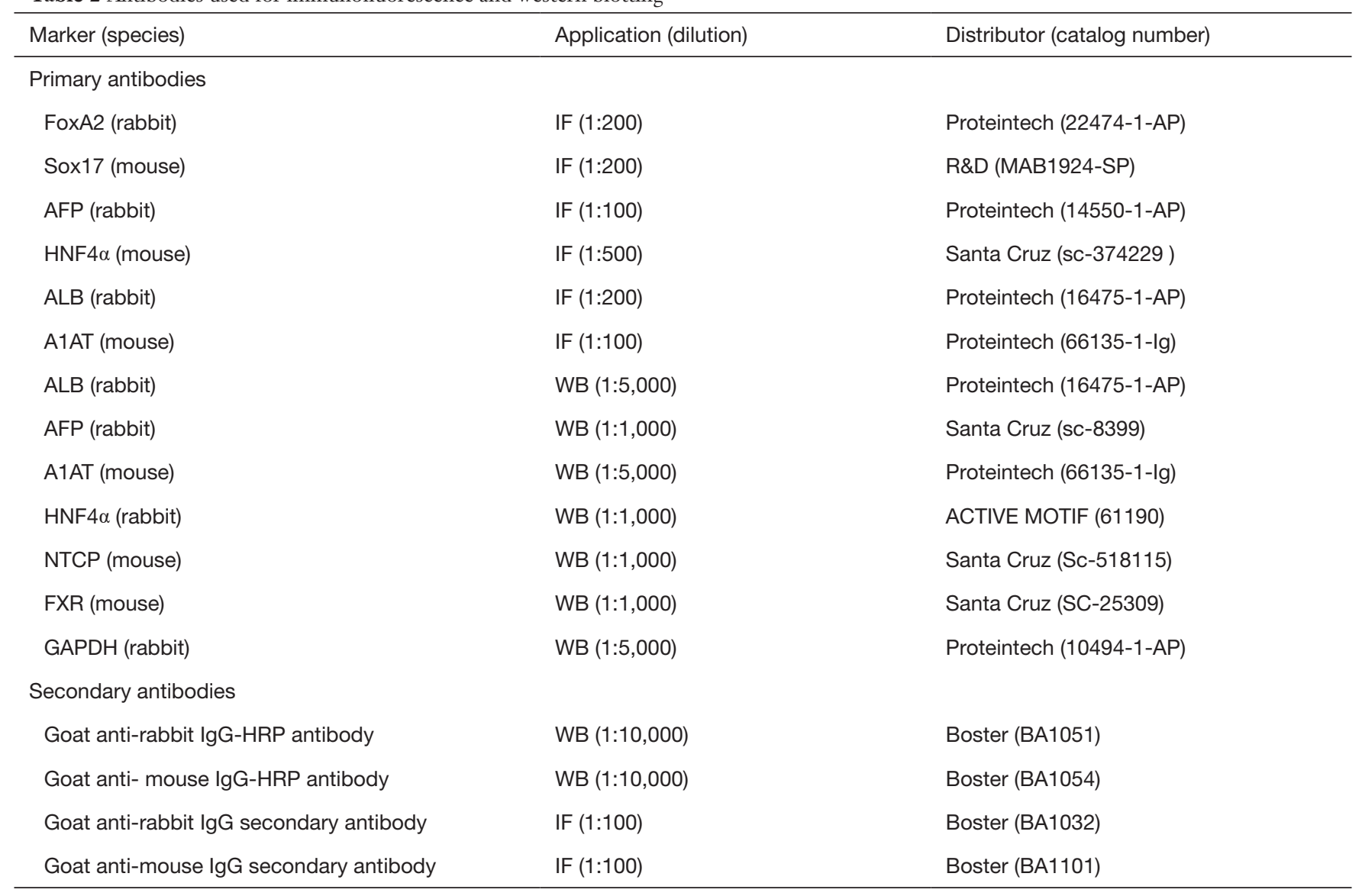

$1 \mathrm{mg} / \mathrm{mL}$. Cells were incubated in diluted ICG for $30 \mathrm{~min}$ at $37^{\circ} \mathrm{C}$. After three washes with PBS, the cellular uptake of ICG was examined by light microscopy.

\section{Low-density lipoprotein (LDL) uptake}

LDL uptake was evaluated by Dil-Ac-LDL staining kit (Beijing Solarbio Science \& Technology Co., Ltd.). Cells were incubated in $20 \mu \mathrm{g} / \mathrm{mL}$ Dil-labeled acetylated LDL for $4 \mathrm{~h}$ at $37^{\circ} \mathrm{C}$, washed three times with PBS and then visualized by fluorescence microscopy using standard rhodamine excitation: emission filters.

\section{Urea production}

At the endpoint of each differentiation group, cells were incubated with IMDM containing $10 \mathrm{mM} \mathrm{NH}_{4} \mathrm{Cl}$ for $24 \mathrm{~h}$, including hHepG2. The supernatants were collected and evaluated using a Quantichrom ${ }^{\mathrm{TM}}$ urea assay kit (Bioassay Systems). A fresh culture medium containing $10 \mathrm{mM}$
$\mathrm{NH}_{4} \mathrm{Cl}$ was used as a negative control.

\section{Statistical analysis}

All data were analyzed using GraphPad Prism 6.0 and displayed as mean $\pm \mathrm{SD}$. Student's $t$-test was used to compare the differences between groups. $\mathrm{P}<0.05$ was considered significant.

\section{Results}

\section{Effect of FH1 on hepatic progenitor cell differentiation}

To determine the effect of FH1 on cell differentiation, we first observed the effect of various concentrations of FH1 on hepatocyte-like differentiation. According to the cell morphology results, FH1 at concentrations of 15 , 30 , and $60 \mu \mathrm{M}$ could induce differentiation, but 3 and $7.5 \mu M$ did not stimulate differentiation. However, with increasing concentration of FH1, the number of dead cells 
A

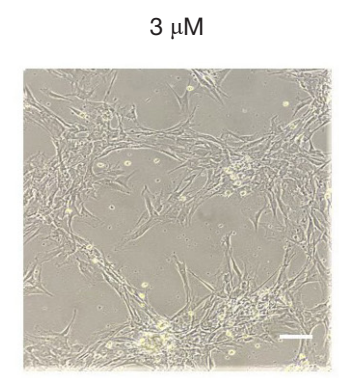

B

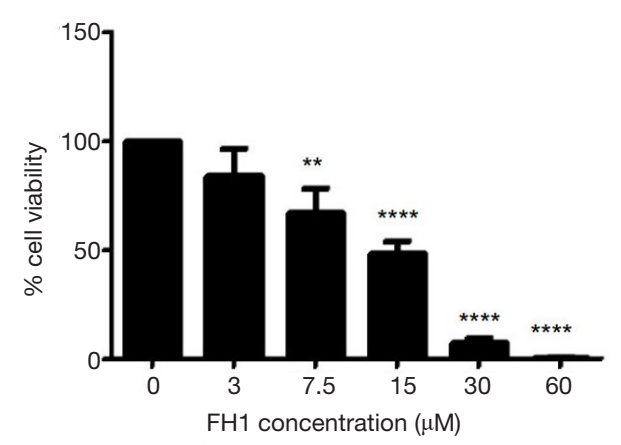

$15 \mu \mathrm{M}$
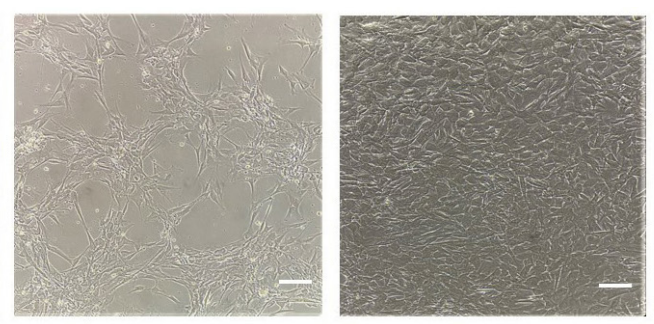

$30 \mu \mathrm{M}$

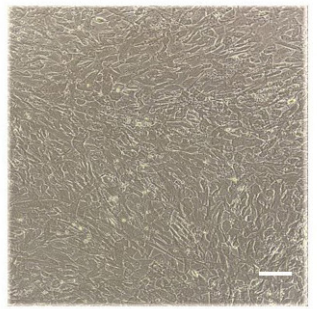

$60 \mu \mathrm{M}$

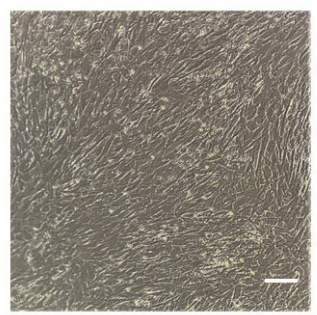

C

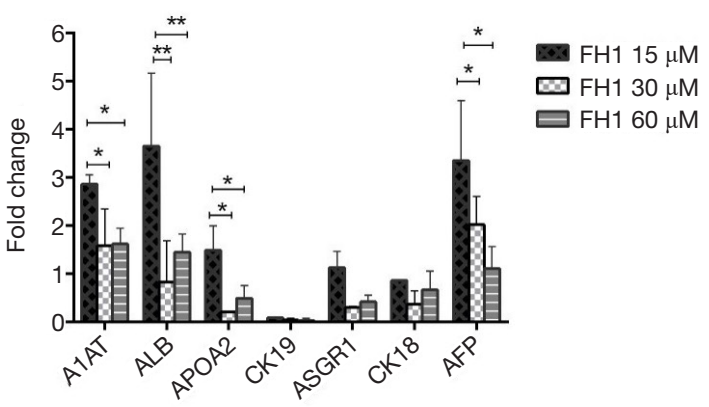

Figure 1 Effect of FH1 treatment during hepatocyte-like cell induction. (A) Cell morphology at different FH1 concentrations. Scale bar $=100 \mu \mathrm{m}$. (B) Effect of FH1 on cytotoxicity of hepatic progenitor cells. Hepatic progenitor cells were cultured with $0-60 \mu \mathrm{M}$ FH1 for 3 days in 96-well plates. The cell viability was assessed via CCK-8 assays. (C) qRT-PCR analysis for hepatocyte-like cell markers using RNA lysates from hepatic progenitor cells exposed to $\mathrm{FH} 1$ at 15, 30, and $60 \mu \mathrm{M}$. All data are presented as the mean of at least three independent experiments. The error bars represent the SD. ${ }^{*} \mathrm{P}$ value $<0.05 ;{ }^{*} \mathrm{P}$ value $<0.01$; ${ }^{* * *} \mathrm{P}$ value $<0.005$. FH1, functional hit 1 ; qRT-PCR, quantitative real-time PCR.

also increased (Figure 1A). Therefore, we investigated the effect of FH1 on cytotoxicity. The hepatic progenitor cells were cultured in IMDM supplemented with FH1 at various concentrations $(0,3,7.5,15,30$, and $60 \mu \mathrm{M})$ for 3 days, and cell survival was detected using a CCK-8 kit. The results showed that the increase in FH1 concentration induced significant toxicity; $\geq 7.5 \mu \mathrm{M}$ caused massive cell death, especially at $\geq 30 \mu M$, where cell viability declined to $5 \%$ (Figure 1B). Finally, we used qRT-PCR (Quantitative real-time PCR) to detect mRNA expression at 15, 30, and $60 \mu \mathrm{M}$ of FH1. Compared with the higher concentrations (30 and $60 \mu \mathrm{M}$ respectively), $\mathrm{FH} 1$ at $15 \mu \mathrm{M}$ showed significantly higher mRNA expression levels of $A 1 A T, A L B$, and $A F P$, which was consistent with previous studies (27) (Figure 1C). Therefore, $15 \mu \mathrm{M}$ was chosen as the optimal concentration to induce hepatocyte maturation.

\section{Induction of definitive endoderm (DE) formation by the combination of SMs related to Wnt/ק-catenin, activin/ nodal, and the PI3K signaling pathway}

The cells were pretreated with ATRA for $24 \mathrm{~h}$ and the culture medium was replaced with IMDM containing IDE1, CHIR99021, and LY294002 for another $24 \mathrm{~h}$ to induce DE formation. At the stage I endpoint (48 h), we observed significant morphological changes, namely acquired a short spindle shape from that of the long fibroblast-like shape (Figure 2A). These changes in morphology were accompanied by upregulation of DE-specific gene markers (Figure 2B) and elevated expression of FOXA2 and SOX17 at the protein level (Figure 2C). qRT-PCR revealed that the mRNA expression of SOX17 and FOXA2 was dramatically higher in cells cultured in the medium containing small molecules compared with those cultured in the growth 
A

Undifferentiated MSC

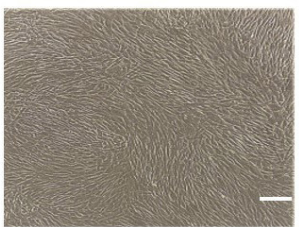

C
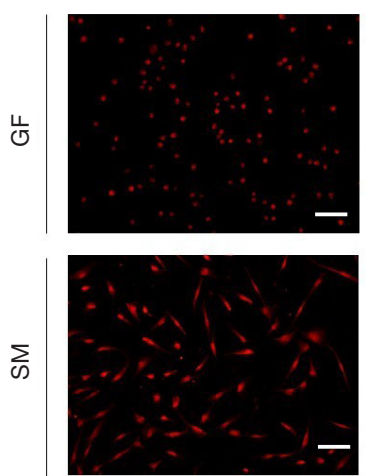

SM

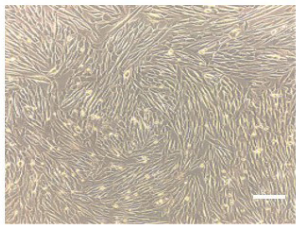

SOX17
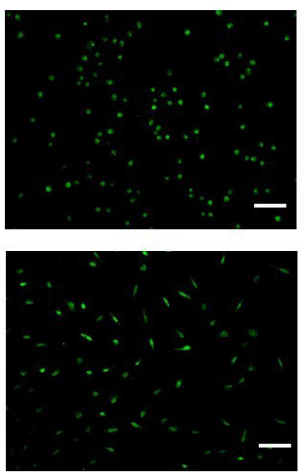

GF

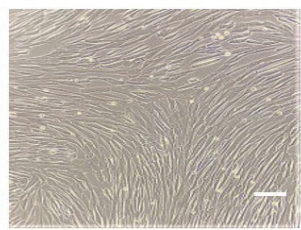

DAPI
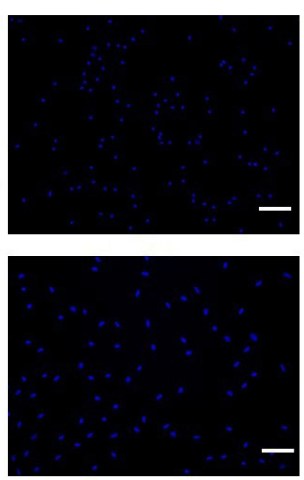

B

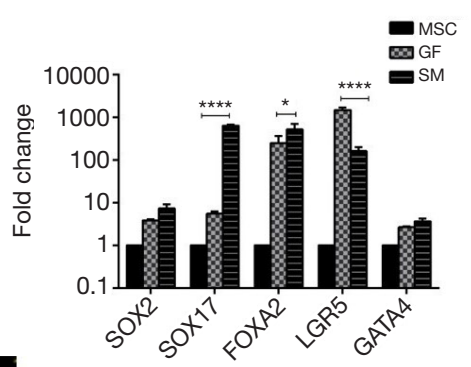

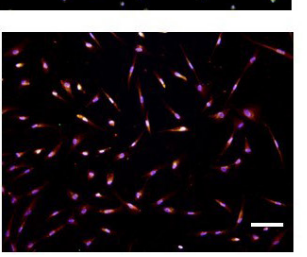

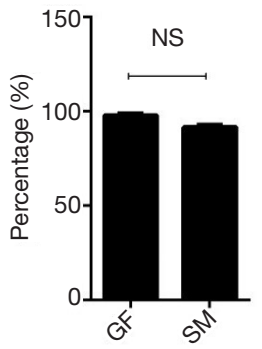

Figure 2 Small molecules efficiently induce hUC-MSC to differentiate to DE. (A) Morphological changes during stage I differentiation. Scale bar $=100 \mu M$. (B) qRT-PCR analysis of the mRNA level expressed during DE differentiation stage. (C) Immunofluorescence of DE marker at day 2 (small molecule-induced DE cells) and day 3 (growth factor-induced DE cells). Scale bar =100 $\mu M$. (D) Percentage of FOXA2+SOX17+ in the immunofluorescence of DE cells. Undifferentiated human MSCs used as control. All data are presented as the mean of at least three independent experiments. ${ }^{*} \mathrm{P}$ value $<0.05$; ${ }^{* * * *} \mathrm{P}$ value $<0.005$. qRT-PCR, quantitative real-time PCR; $\mathrm{SM}$, small molecule; GF, growth factor; MSC, mesenchymal stem cell; DE, definitive endoderm.

factor medium. Immunofluorescent staining showed that the efficiency of DE formation in the SM-treated group was up to $92.52 \%$, according to the expression of FOXA2 and SOX17 (Figure 2D). Collectively, these results demonstrated that the small molecules could induce hUC-MSC to form DE cells.

\section{Effect of bone morphogenetic protein (BMP) inbibitor on differentiation of DE into hepatic progenitor cells}

For the second stage of differentiation, DE cells were treated with IDE1, LDN193189, LY294002, and bFGF for $48 \mathrm{~h}$, and then treated with the same combination without LDN193189 for another $24 \mathrm{~h}$. Gradual changes in cell morphology were observed. The cells acquired a long spindle-like morphology at the endpoint of the second stage (Figure 3A). Furthermore, qRT-PCR analysis demonstrated strong expression of hepatic progenitor markers, including $A F P, H N F 4 \alpha$, and cytokeratin 18 (CK18), in cells cultured in the medium containing the small molecules at the similar levels when compared with cells cultured in the growth factor medium (Figure 3B). The protein expression of AFP and $\mathrm{HNF} 4 \alpha$ was examined by immunofluorescence (Figure 3C). The percentage of AFP and HNF4 $\alpha$ doublepositive cells of the small molecule group was higher than that of the growth factor group (Figure 3D). These results further demonstrated that the small molecule-based differentiation protocol had the same efficacy for inducing DE cell differentiation into hepatic progenitor cells as the GF protocol but in a shorter time.

\section{Rapid generation of induced bepatocyte-like cells by FH1}

When the hepatic progenitor cells differentiating from DE cells were undergoing the final stage of differentiation, we cultured them with three differentiation media: the medium containing small molecules combination of HGF or FH1 and the medium containing growth factor. According to the morphological characterization, there were two changes of the hepatic progenitor cells in this period; briefly, at day 17 (GF) and day 7 (SM + HGF and $\mathrm{SM}+\mathrm{FH} 1)$ of cell differentiation, cells transformed from 
A

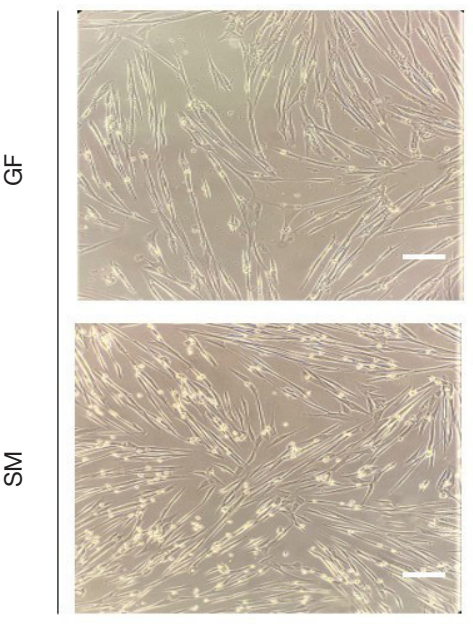

C

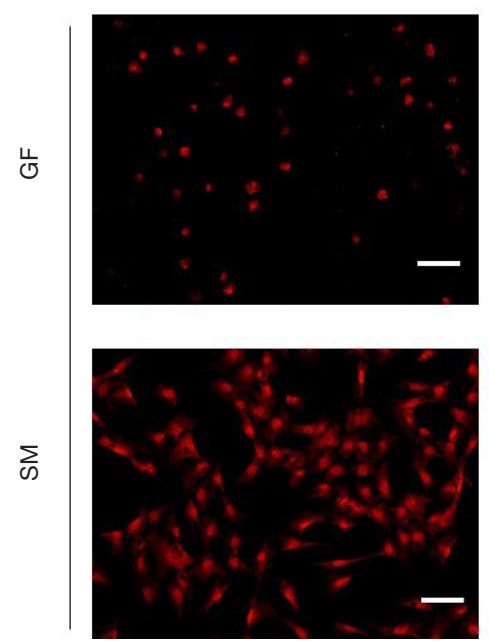

B

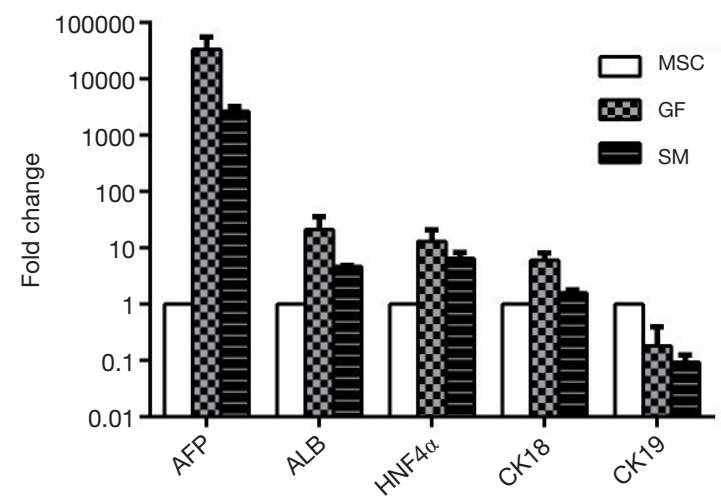

$\mathrm{HNF} 4 \alpha$
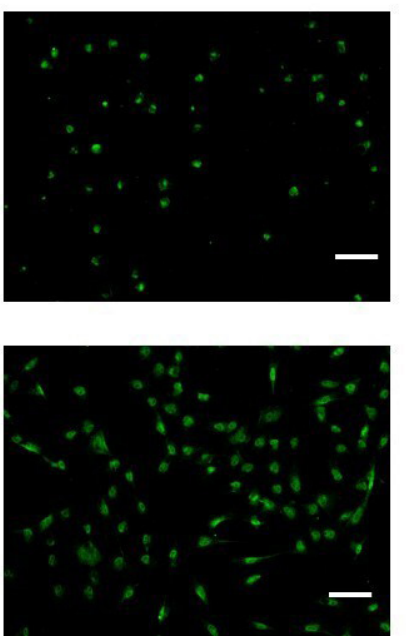

D

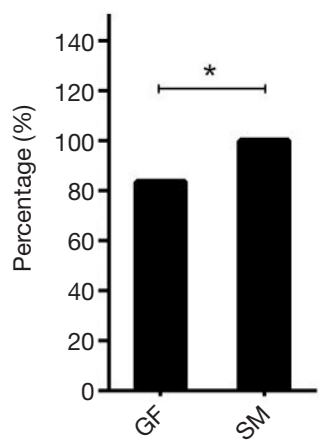

Merge
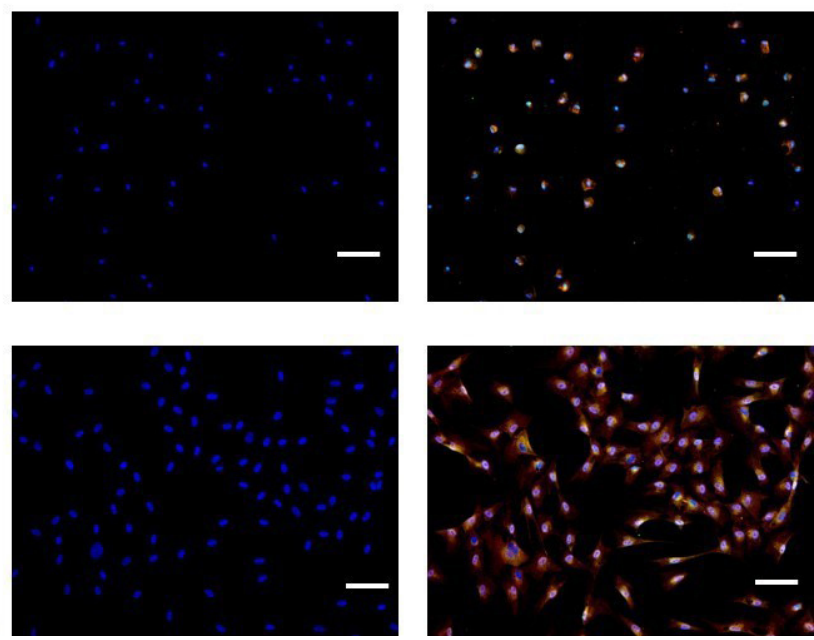

Figure 3 Small molecules efficiently induce DE to differentiate to hepatic progenitors. (A) Morphological changes during hepatic progenitor differentiation. Scale bar $=100 \mu M$. (B) qRT-PCR analysis of the mRNA level of hepatic progenitor specific markers expressed in small molecule or growth-factor groups. (C) Immunofluorescent of AFP and HNF4 $\alpha$ protein level expression at day 5 (small moleculeinduced hepatic progenitor) and day 10 (growth-factor hepatic progenitor). Scale bar $=100 \mu M$. (D) Percentage of AFP $+\mathrm{HNF} 4 \alpha+$ in immunofluorescence of hepatic progenitors. Undifferentiated human MSCs used as control. All data presented as the mean of at least three independent experiments. *P value $<0.05$. qRT-PCR, quantitative real-time PCR; SM, small molecule; GF, growth factor; MSC, mesenchymal stem cell; DE, definitive endoderm.

a long spindle-like morphology into an epithelial-like spherical shape and then acquired a polygonal shape by the endpoint of this stage. These morphological changes occurred in all three groups of differentiated hUC-MSCs (Figure 4A). To analyze the properties of FH1-derived hepatic-like cells, liver-specific markers were detected. Immunofluorescence results showed that the FH1-iHeps exhibited co-expression of the mature hepatocyte markers ALB and A1AT, generating a higher percentage of mature hepatic-like cells (Figure 4B,C). Linked with morphological transformation, the gene expression of mature hepatocyte markers was assayed by qRT-PCR. The mRNA expression levels of $A L B, A 1 A T, A P O A 2$ (apolipoprotein), and ASGR1 in FH1-induced hepatocytes (iHeps) were similar to those in $\mathrm{SM}+\mathrm{HGF}$-induced hepatocytes. Meanwhile, both SM + HGF-induced hepatocytes (SM + HGF-iHep) and SM + FH1-induced hepatocytes (SM + FH1-iHep) expressed the mRNA of hepatitis B virus mediator, which were NTCP 
A

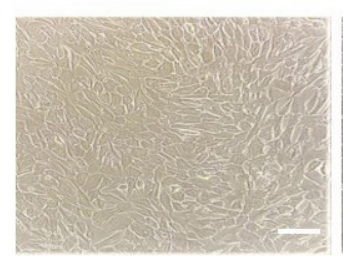

B
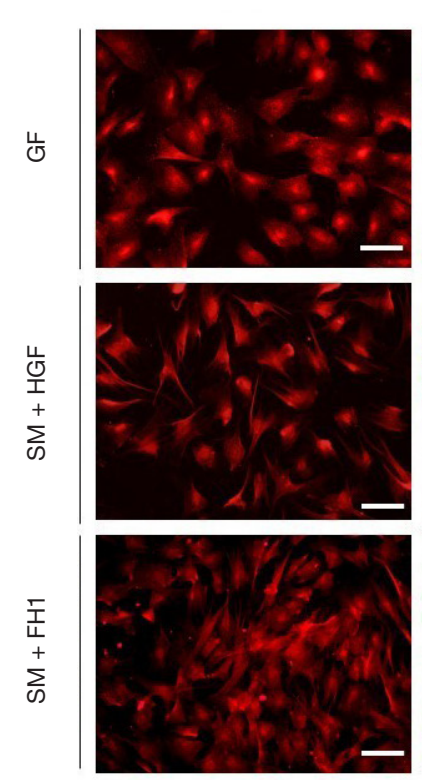

C

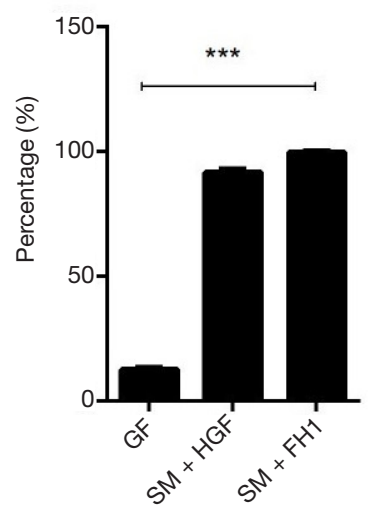

$\mathrm{SM}+\mathrm{HGF}$

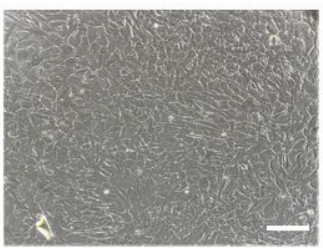

A1AT
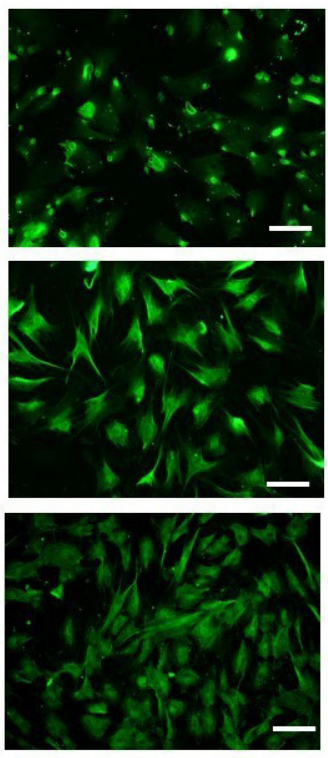

$\mathrm{SM}+\mathrm{FH} 1$

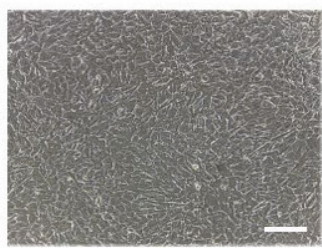

DAPI
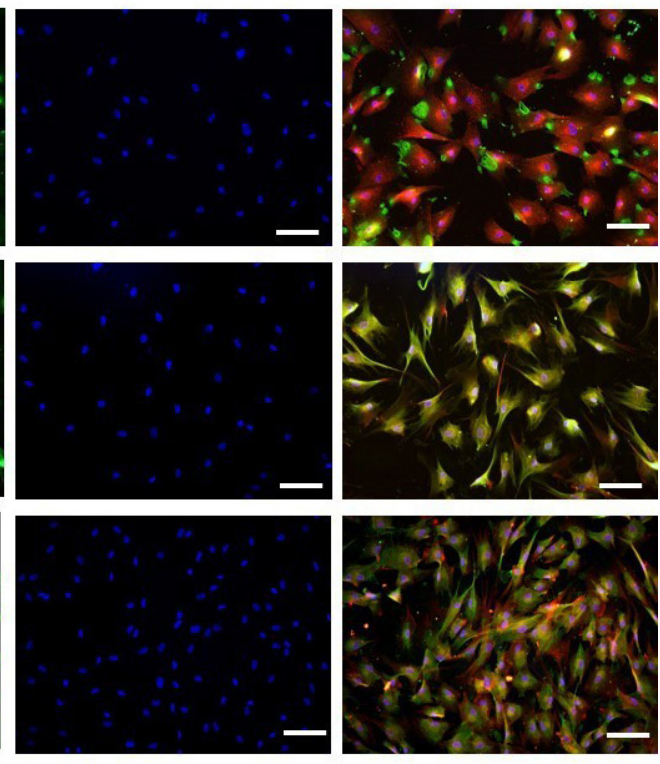

D

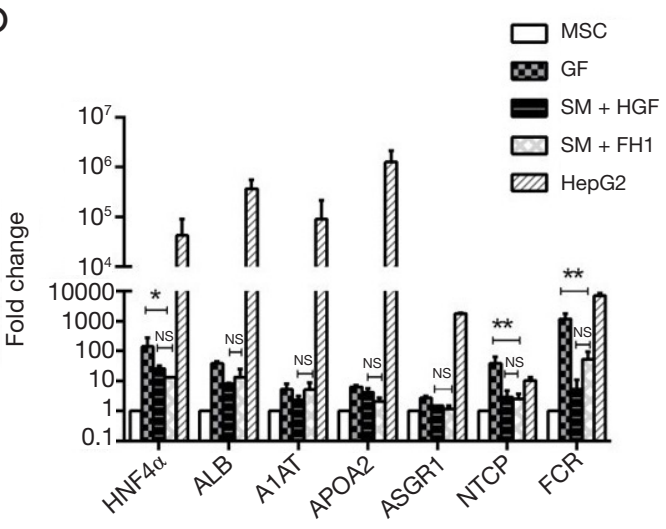

Figure 4 Identification of small molecule combination with HGF- or FH1-induced hepatocyte-like cells. (A) Representative cell morphology of hepatocyte-like cells induced from SM + HGF, SM + FH1, and GF. Scale bar =100 $\mu$ M. (B) Immunofluorescent of ALB and A1AT protein expression levels at day 10 (SM-induced hepatocyte) and day 24 (GF-induced hepatocyte). Scale bar $=100 \mu M$. (C) Percentage of ALB+ A1AT+ in immunofluorescence of hepatocyte cells from three differentiation protocols. (D) qRT-PCR of hepatocytespecific marker expressed in a small molecule with SM + HGF, SM + FH1, and GF. Undifferentiated human MSCs used as control. All data presented as the mean of at least three independent experiments ${ }^{*} \mathrm{P}$ value $<0.05 ;{ }^{* *} \mathrm{P}$ value $<0.01 ;{ }^{* * *} \mathrm{P}$ value $<0.001$. qRT-PCR, quantitative real-time PCR; SM, small molecule; GF, growth factor; HGF, hepatocyte growth factor; FH1, functional hit 1. 
$\left(\mathrm{Na}^{+}\right.$-taurocholate co-transporting polypeptide) and FXR (farnesoid X receptor) positive. However, the hepatocytes that differentiated from the GF-based strategy had a higher mRNA expression of NTCP and FXR than that of SM + FH1 protocol (Figure 4D).

\section{Functions of FH1-iHeps}

PAS staining of cytoplasmic glycogen was performed to measure the hepatocyte-specific functions of FH1-induced cells. The results showed that hepatocytes differentiated by FH1 could store glycogen (Figure $5 A$ ). Moreover, FH1iHeps showed uptake of ICG and acetylated LDL (acLDL), which was used to characterize the function of hepatocellular cells (Figure 5B,C). To assess the metabolic function of ammonia detoxification, we examined urea secretion at the endpoint of the differentiation process; the FH1-treated group displayed higher urea production than the growth factor group did (Figure 5D). Furthermore, we examined hepatocyte-specific protein expression through western blot analysis. The results showed that the levels of these proteins in the cells induced by small molecules were higher than those in cells induced by growth factors (Figure 5E).

Hepatocytes possess the special function of metabolic drug capacity and CYP450 enzyme activity is traditionally used to assess the ability of xenobiotic biotransformation. We quantitatively observed the CYP enzymes CYP1A1, CYP1A2, CYP2C9, CYP2B6, CYP2D6, and CYP3A4 in steps from the three induction strategies. The GF-iHep group expressed a higher mRNA level than the SM + FH1iHep groups. Meanwhile, there was significant difference between $\mathrm{SM}+\mathrm{FH} 1-\mathrm{iHep}$ and $\mathrm{SM}+\mathrm{HGF}-\mathrm{iHep}$ in this capacity (Figure 5F). These results showed that $\mathrm{SM}+\mathrm{FH} 1-$ iHep acquired the functions of primary hepatocytes, and therefore can be used as a cell model for drug screening.

\section{Use of FH1-based differentiation protocol with human iPSC-derived MSC}

To validate the feasibility of the FH1-based differentiation protocol, we further examined whether it could be used with MSC cells derived from other sources. Therefore, we used novel human MSCs generated from human iPSC, which have higher proliferative capacity than primary stem cells (28). To induce definitive endoderm formation, we also pretreated the cells with ATRA for $24 \mathrm{~h}$ and then treated them with IMDM containing IDE1,
CHIR99021, and LY294002 for another $24 \mathrm{~h}$ at the same concentration. After $48 \mathrm{~h}$ of culture, the morphology of the human iPSC-derived MSCs changed significantly, from highly dense, round fusiform to a short spindle shape. In the following $72 \mathrm{~h}$, human iMSC-derived DE were cultured in IMDM supplemented with IDE1, LDN193189, LY294002, and bFGF for hepatic specific differentiation. Interestingly, at the endpoint of stage II, human iMSCderived hepatic progenitors acquired a polygonal shape, which is inconsistent with the morphology of hUC-MSC but similar to the adipose-derived hepatic progenitors. The hepatic progenitor cells were then treated with five compounds, consisting of FH1, Dex, ITS, OSM, and bFGF in Hepatocyte Basal Medium (HBM) for 5 days. As expected, the cell morphology changed to the typical cuboidal shape of mature hepatocytes with tight junctions (Figure 6A). The protein levels of ALB and A1AT were co-expressed in $80 \%$ of the total differentiated cells (Figure 6B,C). Similarly, the iHeps expressed a higher mRNA level of mature hepatocyte markers, including $A L B, A 1 A T, A P O A 2, H N F 4 \alpha$, and ASGR1 (Figure 6D). Importantly, these cells were also able to uptake of ICG (Figure $6 E$ ) and LDL (Figure 6F), stained positive for PAS (Figure 6G), and expressed ALB (Figure 6H), indicating that they had the functions of primary hepatocytes. Interestingly, the undifferentiated human iMSC also showed the ability to take up ICG and LDL.

\section{Discussion}

OLT remains the ideal therapeutic option for acute and chronic liver failure. However, the requirement for OLT is far higher than the availability of liver donors (28). Hepatocyte transplantation could be an alternative method, but the major obstacle is acquiring sufficient primary hepatocytes $(29,30)$. Several studies using MSCs as the cell material to generate hepatocyte-like cells achieved promising outcomes (31-37). Human umbilical cord tissue is the richest source of MSCs, has lower immunogenicity than other adult MSC tissue sources, and can successfully differentiate into all mesodermal lineage cells, including adipocytes, osteocytes, and chondrocytes (10). Therefore, we can use hUC-MSCs to generate hepatocytes instead of those derived from donor's livers. The generation of clinically and scientifically useful hepatocytes requires defined culture conditions that support efficient differentiation of hUC-MSCs into the hepatic lineage. Unfortunately, most of the reported procedures depend on 
A

MSC

GF-iHep

SM + HGF-iHep

$\mathrm{SM}+\mathrm{FH} 1-\mathrm{iHep}$
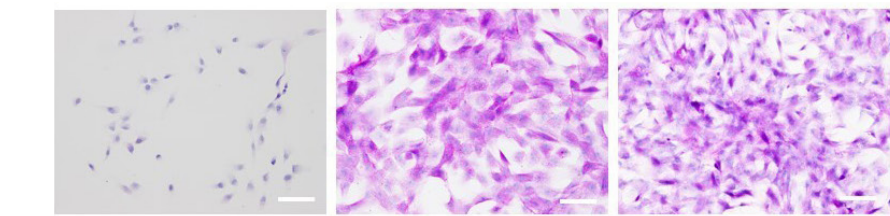

B
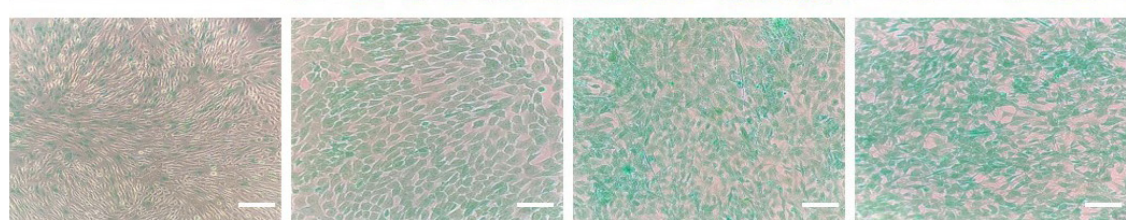

C
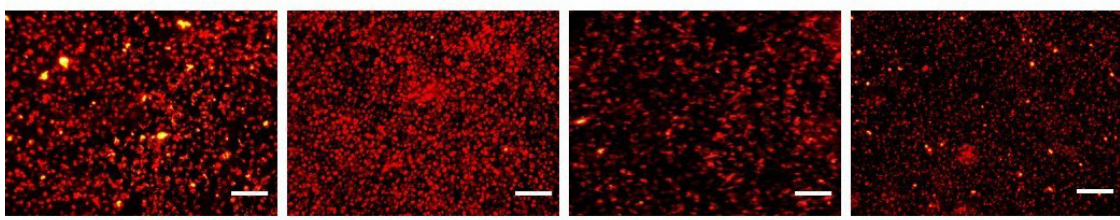

D
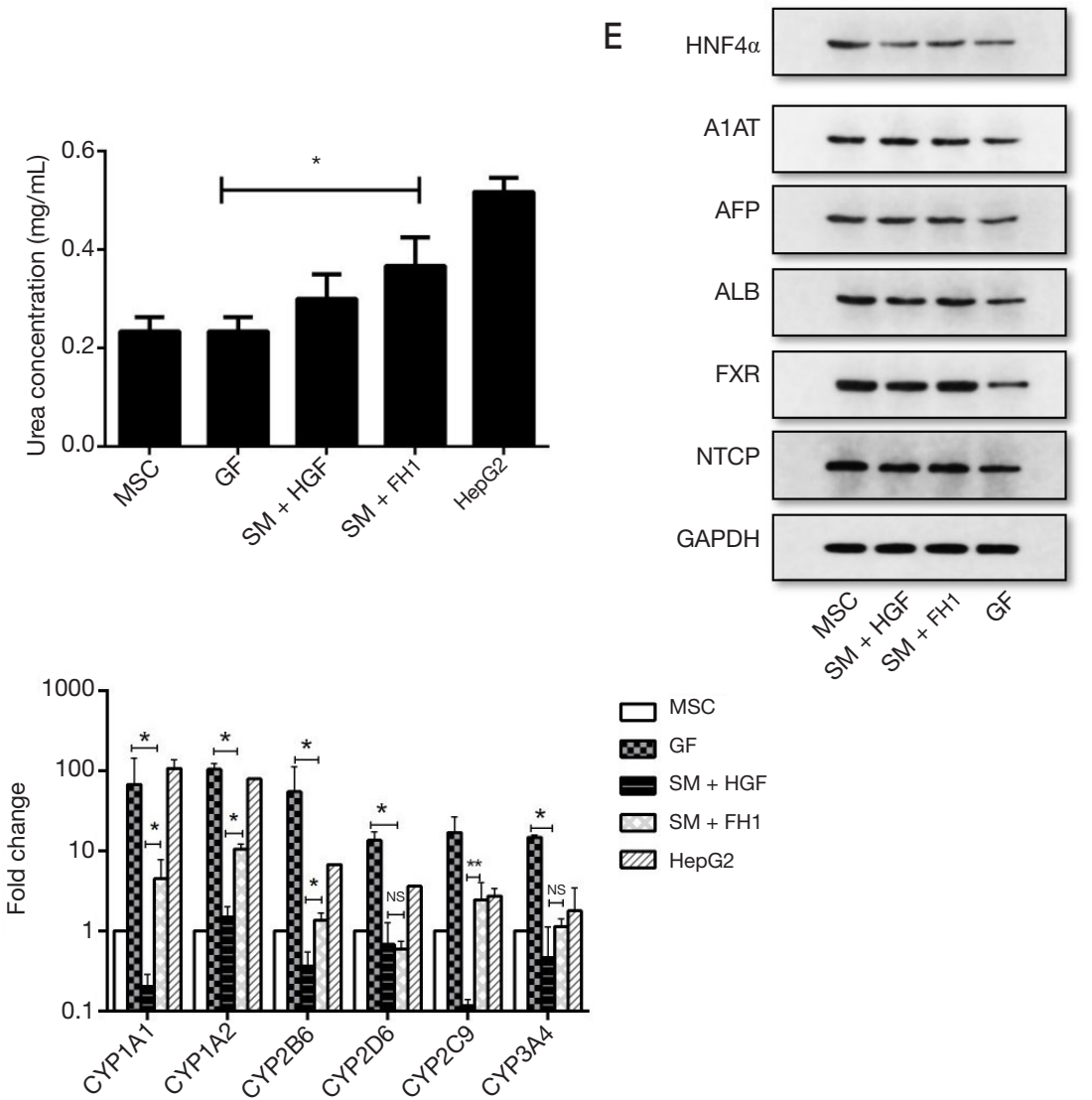

Figure 5 Characterization of small molecule- and growth factor-iHeps. (A) Glycogen storage analysis via PAS staining in small moleculeand growth factor-iHeps. Undifferentiated MSCs used as the control. (B) ICG intake, (C) LDL uptake, scale bar $=100 \mu M$. (D) Urea production, (E) Western blots for ALB, A1AT, HNF4 $\alpha$, AFP, NTXP, and FXR expression. GAPDH used as a control. (F) mRNA levels of CYP genes were determined by qRT-PCR in human hUC-MSC-iHeps. All data are presented as the mean of at least three independent experiments. ${ }^{*} \mathrm{P}$ value $<0.05$; ${ }^{*} \mathrm{P}$ value $<0.01$. qRT-PCR, Quantitative real-time PCR; MSC, mesenchymal stem cell; GF, growth factor; SM, small molecule; HGF, hepatocyte growth factor; iHeps, induced hepatocytes; FH1, functional hit 1. 
A

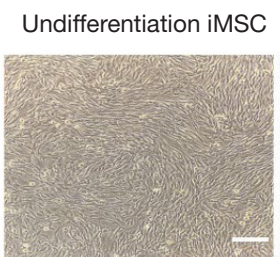

Definitive endoderm

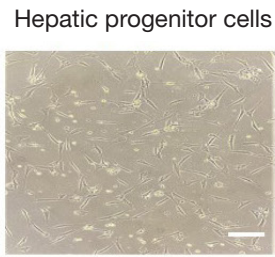

iMSC-iHep

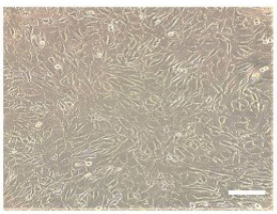

B

ALB

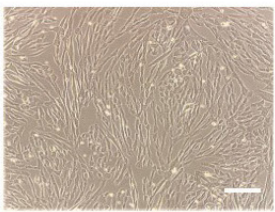

DAPI

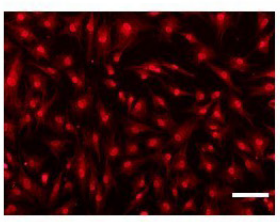

A1AT
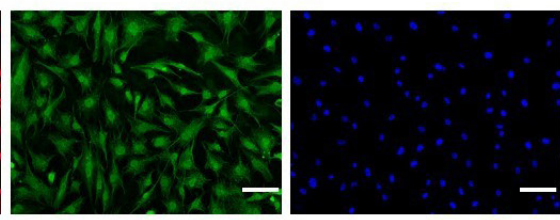

Merge

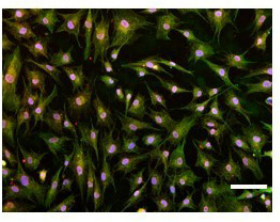

C

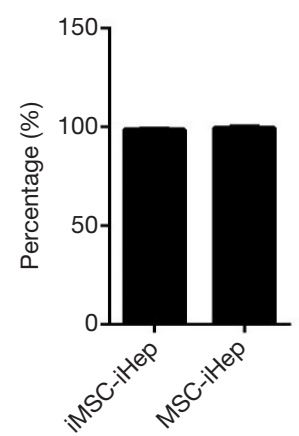

D
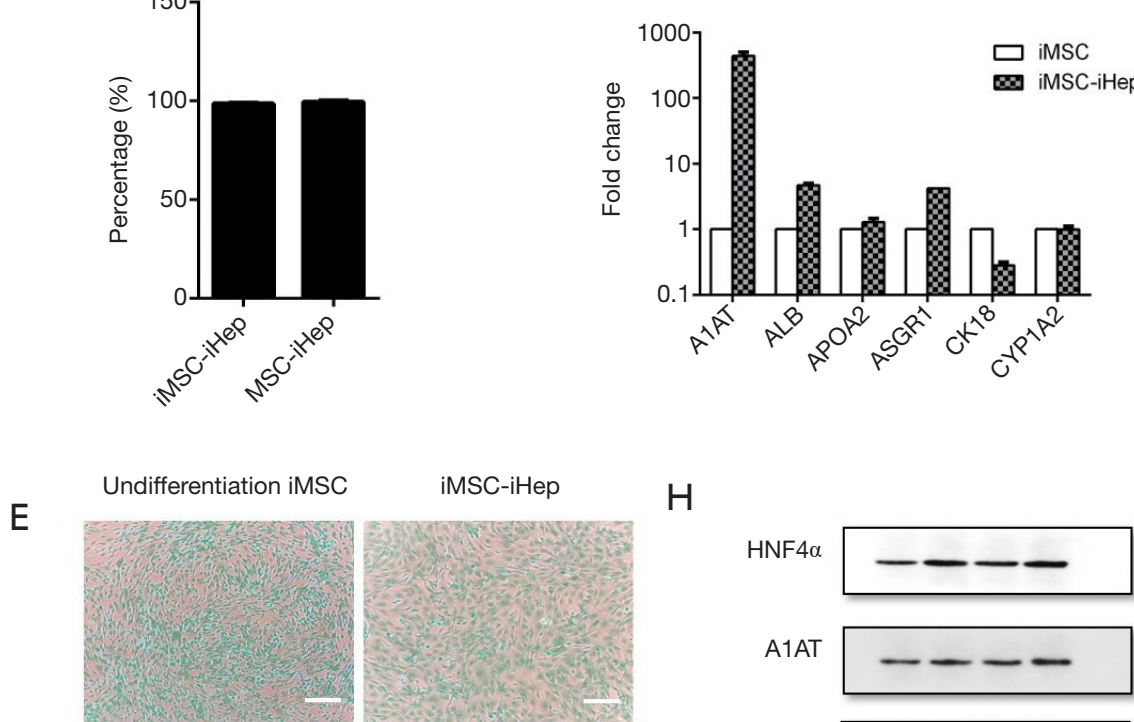

iMSC-iHep

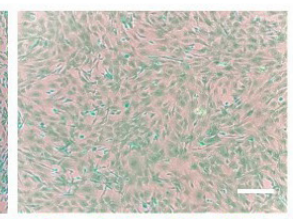

$\mathrm{H}$

F
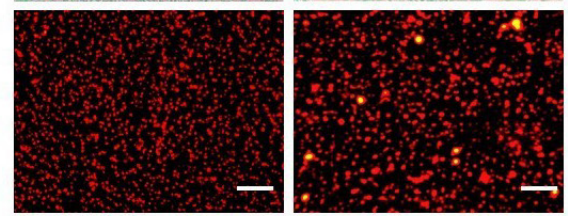

G
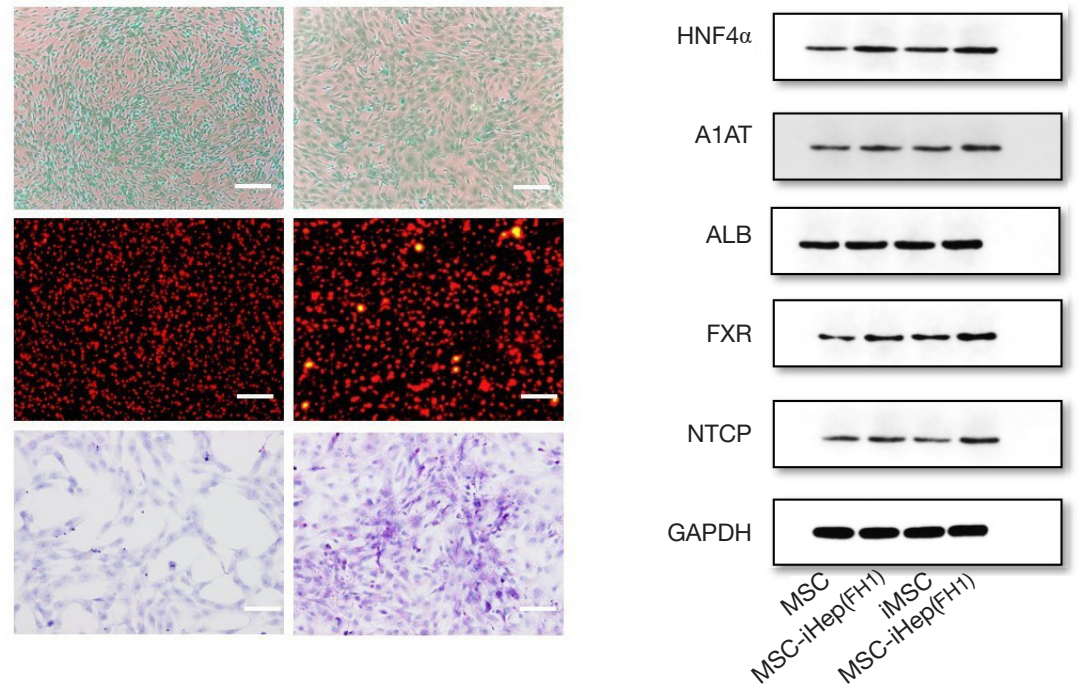

Figure 6 Use of FH1-based differentiation protocol with human iPSC-derived MSCs. (A) Representative cell morphology of hepatocytelike cells induced from human iMSCs. Scale bar $=100 \mu \mathrm{M}$. (B) Immunofluorescence of ALB and A1AT protein expression levels at day 10 in human iMSCs-derived hepatocytes. Scale bar $=100 \mu M$. (C) Percentage of ALB + A1AT + in immunofluorescence of hepatocyte cells from iMSC (D) qRT-PCR of hepatocyte-specific markers expressed in iMSCs-derived hepatocytes. Undifferentiated human MSCs used as control. (E) ICG intake. (F) LDL uptake. (G) Glycogen storage analysis via PAS staining in iMSC-derived hepatocytes. Scale bar $=100 \mu M$. (H) Western blots for ALB, A1AT, HNF4 $\alpha$, NTXP, and FXR expression. GAPDH used as a control. All data are presented as the mean of at least three independent experiments. qRT-PCR, Quantitative real-time PCR; MSC, mesenchymal stem cell; iMSC, induced pluripotent MSCs; iHeps, induced hepatocytes; FH1, functional hit 1. 
adding a large amount of HGF into the culture medium, which is uneconomic to apply therapeutically. Therefore, we wanted to establish a differentiation protocol without the use of HGF and with a modification of the differentiation culture medium.

In this study, we established a 10-day differentiation protocol that rapidly generated hepatocytes from hUCMSCs and human iMSCs using FH1, which has been shown to promote primary hepatocyte expansion in vitro (23). This is a novel report of a fast and HGF-independent protocol able to induce hepatocyte differentiation from hUC-MSCs and human iMSCs.

The development of the liver is a highly dynamic process that mainly involves three stages: endoderm cell specialization to liver lineage cells, liver progenitor cell formation, and liver cell maturation. Therefore, differentiation and maturation of liver cells is a series of complex regulatory processes $(38,39)$ that involves various signal pathways, including $\mathrm{Wnt} / \beta$-catenin, fibroblast growth factor (FGF)/MAPK, TGF- $\beta$, HGF/c-Met, Nodal, BMP, and PI3K $(40,41)$. Based on these recognized signaling pathways, we carefully selected the most promising SMs and experimentally examined their effects.

Hepatocytes originate from the endoderm, and the differentiation of endoderm needs to inhibit activin/nodal, and the PI3K signal pathways and activate $\mathrm{Wnt} / \beta$-catenin signal pathway, which will regulate the expression of SOX17 protein $(20,42)$. CHIR9902 is a GSK3 $\beta$ inhibitor that can activate $\mathrm{Wnt} / \beta$-catenin signaling pathway, which can replace Wnt3a and then initiate DE formation (21,43); LY294002 is the first synthetic inhibitor of the PI3K signal pathway. Therefore, in the formation period of DE, the addition of LY294002 can effectively promote the differentiation of DE (44). IDE 1 is another SM that can trigger DE formation. IDE 1 induces $50 \%$ of human ESCs to differentiate into DE by inhibiting the activin/nodal signal pathway (22).

Following endoderm differentiation, many signal factors continue to play a role in the differentiation into hepatic progenitor cells. The related signaling pathways are activin/ nodal (IDE 1), BMP (LDN193189), and PI3K (LY294002), which are also positively regulated by a fibroblast growth factor (FGF) from the myocardial mesoderm (45). The maturation stage of hepatocytes is the last stage of liver differentiation, in which HGF is very important. Therefore, hepatocyte formation in the hepatocyte maturation stage can be effectively stimulated by adding HGF, OSM, ITS, DEX, and FGF4. Fu et al. successfully induced MSCs from human adipose tissue into hepatocyte-like cells by adding the above compounds in the three stages of hepatocyte differentiation (25). However, whether this induction protocol is suitable for MSCs from other sources has not been reported. Therefore, in this study, we are the first to successfully use this approach to induce the differentiation of hepatocytes from hUC-MSCs. We confirmed that the hUC-MSCs can be induced to differentiate into functional hepatocytes by a combination of SMs and HGF. Although this method dramatically reduces the induction time, HGF is still needed in the stage of hepatocyte maturation. Therefore, we asked whether a small molecular compound could replace HGF.

By screening a compound library, we found that FH1, which was reported for the first time in 2013, can promote the maturation of hepatocytes (23). In 2018, Du et al. successfully induced human iPSCs into hepatocytes without HGF (24). Therefore, we wondered whether FH1 could also replace HGF in the hepatogenic differentiation of human MSCs. We first conducted a FH1 concentration gradient experiment, the various concentration (3, $7.5,15,30$, and $60 \mu \mathrm{M})$ we selected according to the concentration recommended in previous studies and the HGF concentration required by the human adipose-derived hepatocyte strategy. CCK-8 kit was used to detect the effect on cell proliferation. The results of the morphological changes and specific gene expression at the mature stage of hepatocytes confirmed that $15 \mu \mathrm{M}$ of FH1 was the optimum concentration. Meanwhile, three independent experiments showed that FH1 could substitute for HGF in our induction protocol and we successfully induced the MSCs from the human umbilical cord into functional hepatocytes within 10 days. The iHeps not only can express the markers of mature hepatocytes, but also had related functions of primary hepatocytes such as ALB expression, urea synthesis, LDL and ICG uptake, glycogen storage, and drug metabolism. More importantly, these cells can express the HBV receptor proteins NTCP and FXR. Furthermore, to verify the feasibility of this method, we selected MSCs from human iPSC, which generated by the reprograming method from somatic cells, and then successfully differentiated these cells into hepatocytes with similar functions. In conclusion, we successfully established a liver differentiation strategy of stem cell without the need of HGF (Figure 7). The induction strategy greatly reduces the cost of the induction protocol, improves the induction efficiency, and shortens the induction time.

Although FH1 was successfully used to replace HGF in this study, the use of OSM also increased the cost of mass 
A

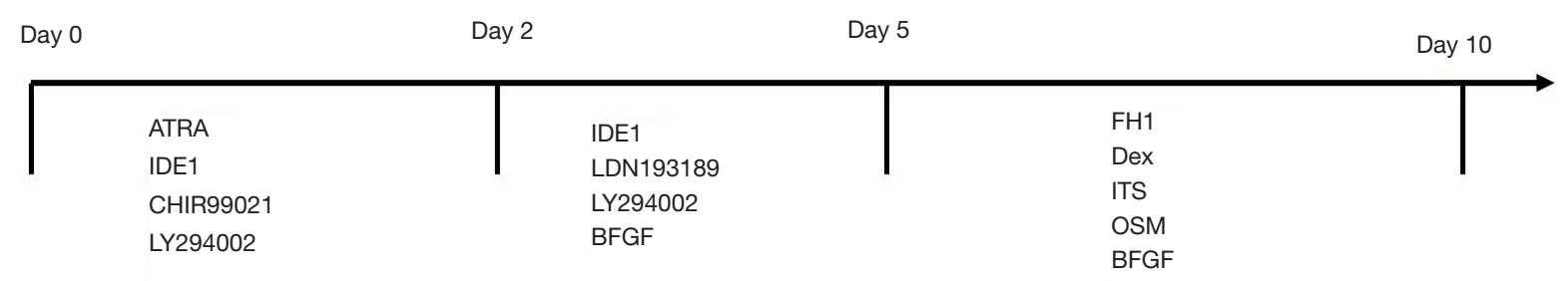

B

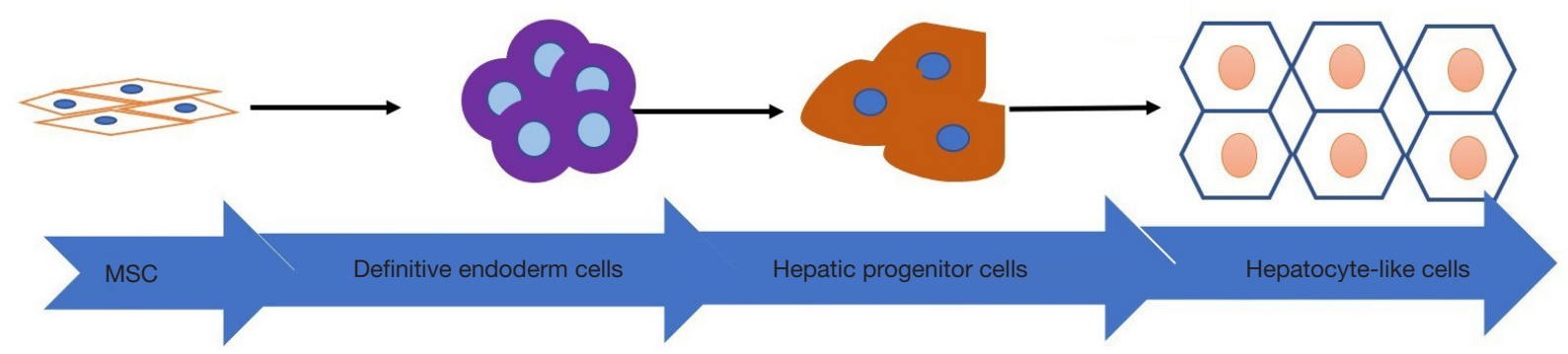

D
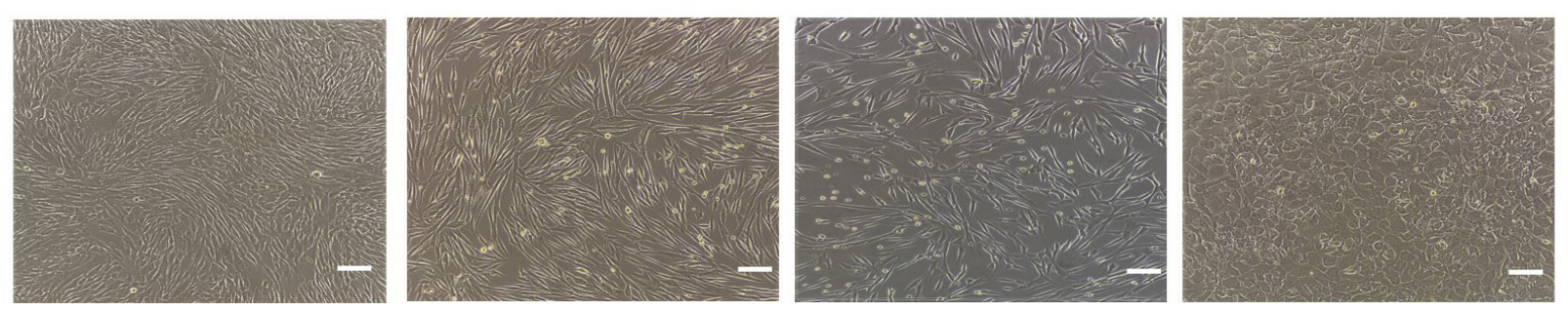

Figure 7 Schematic diagram of the three-stage strategy to induce human MSC differentiation into hepatocytes. (A,B) The detailed hepatocyte differentiation protocol we established using FH1. (C,D) Representative images of morphologic changes during the differentiation process. Scale bar $=100 \mu M$. MSC, mesenchymal stem cell; FH1, functional hit 1 .

production of primary hepatocytes. The combination of functional proliferation hits 1 (FPH1) and FH1 can replace HGF and OSM to promote hepatocyte differentiation of human iPSCs; whether they have the same effect on human MSCs differentiation has not been described. Therefore, it would be interesting to test the effect of the combination of FPH1 and FH1 in this protocol. Above all, SMs promise to replace growth factors and cell factors in stem cell differentiation; it is imperative to find more chemical compounds to optimize the current hepatocyte differentiation approaches to meet clinical needs.

It is worth mentioning that we also found an interesting phenomenon: hUC-MSCs have some of the characteristics and functions of hepatocytes, such as the expression of the ALB, AFP, HNF4A, A1AT, NTCP, and FXR proteins, and uptake of LDL, but cannot uptake ICG or store glycogen. In the meanwhile, human iMSCs also have these functions and can uptake ICG. These observations, which have not been described in previous studies, may explain why MSCs have achieved exciting results in the treatment of clinical liver diseases and obtained the capacity of hepatogenic differentiation. It is also a manifestation of liver function differences caused by different sources of MSCs (i.e., from primary tissue or iPSC).

\section{Conclusions}

We successfully established an HGF-independent strategy for generating hepatocyte-like cells by using FH1. This differentiation method is efficient, time-saving, and economical for generating functional hepatocyte-like cells, providing a cell model for hepatocyte transplantation and virus research.

\section{Acknowledgments}

We are grateful to Professor Yefu Wang and Dr. Jing Yang (Lanzhou University Second Hospital) for their help and valuable suggestions during our study. We thank LetPub (www.letpub.com) for its linguistic assistance during the 
preparation of this manuscript.

Funding: This study was supported by the China Postdoctoral Science Foundation (2016M592375), Hubei Province's Health and Family Planning Scientific Research Project (WJ2017Q002), the Wuhan Enterprise Technology Innovation Project (2018060402011244), and the "Guanggu 3551 Talents" project ( $11^{\text {th }}$ batch; Donghu High-tech Zone, Wuhan, 2018).

\section{Footnote}

Reporting Checklist: The authors have completed the MDAR reporting checklist. Available at https://dx.doi. org/10.21037/atm-21-2829

Data Sharing Statement: Available at https://dx.doi. org/10.21037/atm-21-2829

Conflicts of Interest: All authors have completed the ICMJE uniform disclosure form (available at https://dx.doi. org/10.21037/atm-21-2829). The authors have no conflicts of interest to declare.

Ethical Statement: The authors are accountable for all aspects of the work in ensuring that questions related to the accuracy or integrity of any part of the work are appropriately investigated and resolved.

Open Access Statement: This is an Open Access article distributed in accordance with the Creative Commons Attribution-NonCommercial-NoDerivs 4.0 International License (CC BY-NC-ND 4.0), which permits the noncommercial replication and distribution of the article with the strict proviso that no changes or edits are made and the original work is properly cited (including links to both the formal publication through the relevant DOI and the license). See: https://creativecommons.org/licenses/by-nc-nd/4.0/.

\section{References}

1. Bernal W, Wendon J. Acute liver failure. N Engl J Med 2013;369:2525-34.

2. Kim WR, Lake JR, Smith JM, et al. OPTN/SRTR 2015 Annual Data Report: Liver. Am J Transplant 2017;17 Suppl 1:174-251.

3. Banas A, Teratani T, Yamamoto Y, et al. Adipose tissuederived mesenchymal stem cells as a source of human hepatocytes. Hepatology 2007;46:219-28.

4. Woo DH, Kim SK, Lim HJ, et al. Direct and indirect contribution of human embryonic stem cellderived hepatocyte-like cells to liver repair in mice. Gastroenterology 2012;142:602-11.

5. Tang X, Li W, Wen X, et al. Transplantation of dental tissue-derived mesenchymal stem cells ameliorates nephritis in lupus mice. Ann Transl Med 2019;7:132.

6. Romanov YA, Darevskaya AN, Merzlikina NV, et al. Mesenchymal stem cells from human bone marrow and adipose tissue: isolation, characterization, and differentiation potentialities. Bull Exp Biol Med 2005;140:138-43.

7. Troyer DL, Weiss ML. Wharton's jelly-derived cells are a primitive stromal cell population. Stem Cells 2008;26:591-9.

8. Xu Z, Zhou X, Wu J, et al. Mesenchymal stem cellderived exosomes carrying microRNA-150 suppresses the proliferation and migration of osteosarcoma cells via targeting IGF2BP1. Transl Cancer Res 2020;9:5323-35.

9. Kestendjieva S, Kyurkchiev D, Tsvetkova G, et al. Characterization of mesenchymal stem cells isolated from the human umbilical cord. Cell Biol Int 2008;32:724-32.

10. Karahuseyinoglu S, Cinar O, Kilic E, et al. Biology of stem cells in human umbilical cord stroma: in situ and in vitro surveys. Stem Cells 2007;25:319-31.

11. Ong SY, Dai H, Leong KW. Inducing hepatic differentiation of human mesenchymal stem cells in pellet culture. Biomaterials 2006;27:4087-97.

12. Ishii K, Yoshida Y, Akechi Y, et al. Hepatic differentiation of human bone marrow-derived mesenchymal stem cells by tetracycline-regulated hepatocyte nuclear factor 3 beta. Hepatology 2008;48:597-606.

13. Hashemi SM, Soleimani M, Zargarian SS, et al. In vitro differentiation of human cord blood-derived unrestricted somatic stem cells into hepatocyte-like cells on poly(epsilon-caprolactone) nanofiber scaffolds. Cells Tissues Organs 2009;190:135-49.

14. Ji R, Zhang N, You N, et al. The differentiation of MSCs into functional hepatocyte-like cells in a liver biomatrix scaffold and their transplantation into liver-fibrotic mice. Biomaterials 2012;33:8995-9008.

15. Hu C, Li L. In Vitro and In Vivo Hepatic Differentiation of Adult Somatic Stem Cells and Extraembryonic Stem Cells for Treating End Stage Liver Diseases. Stem Cells Int 2015;2015:871972.

16. Li W, Li K, Wei W, et al. Chemical approaches to 
stem cell biology and therapeutics. Cell Stem Cell 2013;13:270-83.

17. Liu K, Yu C, Xie M, et al. Chemical Modulation of Cell Fate in Stem Cell Therapeutics and Regenerative Medicine. Cell Chem Biol 2016;23:893-916.

18. Zhang Y, Li W, Laurent T, et al. Small molecules, big roles -- the chemical manipulation of stem cell fate and somatic cell reprogramming. J Cell Sci 2012;125:5609-20.

19. Hay DC, Fletcher J, Payne C, et al. Highly efficient differentiation of hESCs to functional hepatic endoderm requires ActivinA and Wnt3a signaling. Proc Natl Acad Sci U S A 2008;105:12301-6.

20. Touboul T, Chen S, To CC, et al. Stage-specific regulation of the WNT/ $\beta$-catenin pathway enhances differentiation of hESCs into hepatocytes. J Hepatol 2016;64:1315-26.

21. Bone HK, Nelson AS, Goldring CE, et al. A novel chemically directed route for the generation of definitive endoderm from human embryonic stem cells based on inhibition of GSK-3. J Cell Sci 2011;124:1992-2000.

22. Kim SW, Yoon SJ, Chuong E, et al. Chromatin and transcriptional signatures for Nodal signaling during endoderm formation in hESCs. Dev Biol 2011;357:492-504.

23. Shan J, Schwartz RE, Ross NT, et al. Identification of small molecules for human hepatocyte expansion and iPS differentiation. Nat Chem Biol 2013;9:514-20.

24. Du C, Feng Y, Qiu D, et al. Highly efficient and expedited hepatic differentiation from human pluripotent stem cells by pure small-molecule cocktails. Stem Cell Res Ther 2018;9:58.

25. Fu Y, Deng J, Jiang Q, et al. Rapid generation of functional hepatocyte-like cells from human adipose-derived stem cells. Stem Cell Res Ther 2016;7:105.

26. Campard D, Lysy PA, Najimi M, et al. Native umbilical cord matrix stem cells express hepatic markers and differentiate into hepatocyte-like cells. Gastroenterology 2008;134:833-48.

27. Sabapathy V, Kumar S. hiPSC-derived iMSCs: NextGen MSCs as an advanced therapeutically active cell resource for regenerative medicine. J Cell Mol Med 2016;20:1571-88.

28. Lee WM, Squires RH Jr, Nyberg SL, et al. Acute liver failure: Summary of a workshop. Hepatology 2008;47:1401-15.

29. Mitaka T. The current status of primary hepatocyte culture. Int J Exp Pathol 1998;79:393-409.

30. Hu C, Li L. In vitro culture of isolated primary hepatocytes and stem cell-derived hepatocyte-like cells for liver regeneration. Protein Cell 2015;6:562-74.

31. Wang HS, Hung SC, Peng ST, et al. Mesenchymal stem cells in the Wharton's jelly of the human umbilical cord. Stem Cells 2004:22:1330-7.

32. Baksh D, Yao R, Tuan RS. Comparison of proliferative and multilineage differentiation potential of human mesenchymal stem cells derived from umbilical cord and bone marrow. Stem Cells 2007;25:1384-92.

33. Zhang YN, Lie PC, Wei X. Differentiation of mesenchymal stromal cells derived from umbilical cord Wharton's jelly into hepatocyte-like cells. Cytotherapy 2009;11:548-58.

34. Zhang S, Yang Y, Fan L, et al. The clinical application of mesenchymal stem cells in liver disease: the current situation and potential future. Ann Transl Med 2020;8:565.

35. Yoon HH, Jung BY, Seo YK, et al. In vitro hepatic differentiation of umbilical cord-derived mesenchymal stem cell. Process Biochemistry 2010;45:1857-64.

36. Prasajak P, Leeanansaksiri W. Developing a New TwoStep Protocol to Generate Functional Hepatocytes from Wharton's Jelly-Derived Mesenchymal Stem Cells under Hypoxic Condition. Stem Cells Int 2013;2013:762196.

37. An SY, Han J, Lim HJ, et al. Valproic acid promotes differentiation of hepatocyte-like cells from whole human umbilical cord-derived mesenchymal stem cells. Tissue Cell 2014;46:127-35.

38. Zaret KS, Watts J, Xu J, et al. Pioneer factors, genetic competence, and inductive signaling: programming liver and pancreas progenitors from the endoderm. Cold Spring Harb Symp Quant Biol 2008;73:119-26.

39. Zaret KS. Genetic programming of liver and pancreas progenitors: lessons for stem-cell differentiation. Nat Rev Genet 2008;9:329-40.

40. Gordillo M, Evans T, Gouon-Evans V. Orchestrating liver development. Development 2015;142:2094-108.

41. Si-Tayeb K, Lemaigre FP, Duncan SA. Organogenesis and development of the liver. Dev Cell 2010;18:175-89.

42. Engert S, Burtscher I, Liao WP, et al. Wnt/ $\beta$-catenin signalling regulates Sox 17 expression and is essential for organizer and endoderm formation in the mouse. Development 2013;140:3128-38.

43. Siller R, Greenhough S, Naumovska E, et al. Smallmolecule-driven hepatocyte differentiation of human pluripotent stem cells. Stem Cell Reports 2015;4:939-52.

44. Touboul T, Hannan NR, Corbineau S, et al. Generation of functional hepatocytes from human embryonic stem cells 
under chemically defined conditions that recapitulate liver development. Hepatology 2010;51:1754-65.

45. Calmont A, Wandzioch E, Tremblay KD, et al. An FGF response pathway that mediates hepatic gene induction in embryonic endoderm cells. Dev Cell 2006;11:339-48.

(English Language Editor: K. Brown)

Cite this article as: Luo S, Ai Y, Xiao S, Wang B, Wang Y. Functional hit 1 (FH1)-based rapid and efficient generation of functional hepatocytes from human mesenchymal stem cells: a novel strategy for hepatic differentiation. Ann Transl Med 2021;9(13):1087. doi: 10.21037/atm-21-2829 